\title{
One step forward or one step back? Autonomy, agency and surrogates in the Indian Surrogacy (Regulation) Bill 2019
}

\author{
Swati Gola* \\ Lecturer, School of Law, University of Exeter, UK \\ ${ }^{*}$ Corresponding author. E-mail: golaswati@gmail.com
}

\begin{abstract}
The Indian government has recently introduced legislation to regulate 'altruistic' surrogacy while banning 'commercial' surrogacy amidst the criticism that India has become the 'baby factory'. In the past decade, academic discourse has raised socioethical and legal issues that surfaced in the unrestricted transnational commercial-surrogacy industry. Most of the literature and ethnographic studies centred on the issues of informed consent, autonomy, decision-making and exploitation. With the proposed legislation, the Indian government has shown its will to regulate surrogacy, including the medical intermediaries as well as the contract between the intending parents and the surrogate mother-to-be. The present paper addresses the legal and socioethical context in which India introduced the Surrogacy (Regulation) Bill 2019. It examines the extent to which the proposed law responds to the legal challenges and socioethical concerns that surfaced in the course of unregulated transnational commercial-surrogacy arrangements in India. It argues that, even though the proposed legislation addresses and responds to some of the legal and ethical concerns such as informed consent and legal parentage, it stops short of ensuring the welfare and well-being of the surrogate. Second, the legal certainty of parentage and the child's rights comes at the cost of the physical and psychological well-being of the surrogate. Finally, it argues that, by presupposing the surrogate as an autonomous agent and yet imposing the requirement of marriage, the Bill overlooks the sociocultural realities of patriarchal hierarchies entrenched in Indian society - that, in its conception of 'family', the focus on the 'traditional' family not only presents a narrow view of the heteronormative family and perpetuates the patriarchal notions of gender roles, but also fails to take into consideration maternal pluralism in surrogacy arrangements, undermines the modern family and, above all, discriminates against the single person's and lesbian, gay, bisexual, transgender, and queer (LGBTQ) communities' right to found a family. Since many countries that served as centres for international commercial-surrogacy arrangement (such as Cambodia, Thailand and Nepal) have recently started to take steps to prohibit or limit transnational surrogacy arrangements, the analysis of Indian law in the present paper will provide a useful context within which these countries can effectively regulate surrogacy while safeguarding the surrogate's rights and interests.
\end{abstract}

Keywords: family law; ethics; surrogate's rights; reproductive autonomy; informed consent

\section{Introduction}

Reproductive tourism, namely the movement of people to another country with the intention of having a child using assisted reproductive technologies (ARTs) and surrogacy, came to public attention following the newspaper stories and documentaries of successful births, happy families and surrogates, and suitable destinations (see e.g. O'Connor, 2007; Haworth, 2007; Google Baby, 2009 (a documentary directed by Zippi Brand Frank, Films Transit International, Israel)) and cases like Baby Manji Yamada v. Union of India (2008 (13) SCC 518) and Jan Balaz v. Anand Municipality \& others (Gujarat H.C. 2009) that raised novel legal questions of parentage, citizenship, etc. The absence of any regulatory

(C) The Author(s), 2021. Published by Cambridge University Press. This is an Open Access article, distributed under the terms of the Creative Commons Attribution licence (http://creativecommons.org/licenses/by/4.0/), which permits unrestricted re-use, distribution, and reproduction in any medium, provided the original work is properly cited. 
framework along with much lower costs, ${ }^{1}$ English-speaking medical staff, state-of-the-art medical services and an abundance of poor women willing to act as surrogates soon made India a global destination for fertility treatment and commercial surrogacy. In the past decade, academic literature emerged that raised socioethical and legal issues in the unrestricted transnational commercial-surrogacy industry (see e.g. Pande, 2009; Jaiswal, 2012; Gola, 2013). Most of the literature and ethnographic studies centred on the issues of informed consent, autonomy, decision-making and exploitation (e.g. Tanderup et al., 2015; Centre for Social Research, 2012; SAMA, 2012). Following the criticism that India was turning into a 'global baby factory' (Twine, 2015), the Indian government in 2015 banned commercial surrogacy for foreign nationals including non-resident Indians with foreign national status, although domestic commercial surrogacy was still ongoing (Government of India, 2017a). In 2019, the Indian government introduced the legislation to regulate 'altruistic' surrogacy while maintaining the prohibition over 'commercial' surrogacy. With the passage of the Surrogacy (Regulation) Bill 2019 (hereafter 'the Bill') in the lower house of the parliament, ${ }^{2}$ the Indian government has shown its will to regulate surrogacy, the medical intermediaries as well as the contracts between the intending parents and the surrogate mother-to-be.

The present paper explores the extent to which the proposed law responds to the legal challenges and socioethical concerns raised in the course of unregulated transnational commercial-surrogacy arrangements in India. To that end, it first sets out the legal and socioethical context in which India introduced the Surrogacy (Regulation) Bill 2019 followed by an analysis of the Bill within this context. It argues that, even though the proposed legislation addresses and responds to some of the legal and socioethical concerns such as legal parentage and informed consent, it fails to ensure the welfare and well-being of the surrogate. Second, the paper argues that the legal certainty of parentage and the child's rights come at the cost of the physical and psychological well-being of the surrogate. Finally, the paper argues that, by presupposing that the surrogate is an autonomous agent and yet imposing the requirement of marriage, the Bill displays an inexplicable duality. It further overlooks the sociocultural realities of patriarchal hierarchies entrenched in Indian society where a married woman's autonomy is relational and severely constrained. Moreover, in its conception of 'family', the focus on 'traditional' family not only presents a narrow view of a heteronormative ${ }^{3}$ family and perpetuates the patriarchal notions of gender roles, but also fails to take into consideration maternal pluralism in surrogacy arrangements. This arguably undermines a more open concept of the modern family and above all discriminates against the single person's, and particularly the lesbian, gay, bisexual, transgender, and queer (LGBTQ) community's, right to found a family. Since many countries that have also served as centres for international commercial-surrogacy arrangements (such as Cambodia, Thailand and Nepal) have recently started to take steps to prohibit or limit them, the analysis of Indian law in the present paper identifies some key legal and ethical parameters within which these countries can effectively regulate surrogacy while also safeguarding surrogates' rights and interests.

\section{Legal and socioethical challenges of unregulated commercial surrogacy}

A surrogacy arrangement in essence entails legal and physical transfer of the child by the surrogate mother to the intending parent(s) without retaining parentage or parental responsibility (UN Report, 2018, p. 3). Although surrogacy arrangements are contractual in nature, they generally occur within the context of ARTs, such as gamete intra-fallopian transfer (GIFT), pro-nuclear transfer

\footnotetext{
${ }^{1}$ Whereas a surrogacy package costs from US $\$ 40,000$ to US $\$ 150,000$ in the US, surrogacy in India costs from US $\$ 25,000$ to US $\$ 30,000$. The surrogate receives somewhere between US\$6,000 and US\$10,000, and the rest of the sum is paid to the fertility clinics or other middleperson. For more, see Jaiswal (2012).

${ }^{2}$ It will be enacted as law as soon as it is passed by the upper house of the parliament (Rajya Sabha) and receives the assent of the president.

${ }^{3}$ Heteronormativity describes a system through which certain heterosexual practices are normalised and 'privileged' through a continual repetition of particular, naturalised constructions of gender, sexuality and the family (Smith, 2015, p. 236).
} 
(PNT), in-vitro fertilisation (IVF) and embryo transfer for gestational (or full) surrogacy (where the surrogate mother is genetically unrelated to the child) or artificial insemination for traditional (or partial) surrogacy (wherein the surrogate mother is genetically related to the child). Advances in ARTs mean that it is no longer necessary to use gametes from either the intending parent(s) or the surrogate mother, as gametes can now be purchased from or 'donated' by additional parties (UN Report, 2018, p. 3). Following the policy inclination towards trade liberalisation, absence of any regulatory framework, special 'medical visas', state-of-the-art medical facilities, English-speaking medical professionals and poor, desperate yet fertile surrogates, India soon emerged as a top destination for international commercial surrogacy (Deonandan et al., 2012).

Unchecked international commercial-surrogacy arrangements soon raised novel legal questions of citizenship, nationality and parentage in situations that were covered neither by surrogacy contracts nor by any existing laws (Gola, 2013). In the absence of surrogacy-specific laws in India, these surrogacy arrangements operated within the pre-existing laws governing parentage, termination of parental rights and adoption that were not adequate to deal with novel challenges posed by commercialsurrogacy contracts between foreign intending parents and Indian surrogates. For example, who shall have the parental responsibilities and rights over the surrogate-born child: the surrogate as the birthing mother or the commissioning parents for having the genetic ties? What will be the position where the commissioning couple do not have the genetic ties with the child, namely cases in which donor gametes are used? The problem is further accentuated where intending parent(s) intentionally evaded prohibitionist laws of the country of their residence and created dilemmas for competent authorities as seen in both the Baby Manji and Jan Balaz cases. Consequently, the judiciary in India were placed in situation of being asked to validate international surrogacy arrangements that were illegal in other jurisdictions. The obligation to protect the rights of surrogate-born children along with sympathy for intending parent(s) and their wish to form a family further added to the complications (UN Report, 2018, p. 6).

In terms of socioethical concerns, exercise of autonomy, agency and informed consent (or lack thereof) by the surrogate emerged as the central issues in commercial-surrogacy arrangements in India (Gomez, 2014; Majumdar, 2014; Wilkinson, 2016; Rozée et al., 2019; Tanderup et al., 2015). Ethnographic studies compiling lived experiences of surrogates from different parts of India (ranging from Punjab and Delhi in north India to Bengaluru in the south) further provided a deeper insight, evidentiary value as well as a more nuanced and complex portrayal of these issues. As opposed to surrogates in the US, the UK or Israel (where surrogates have autonomy and the power to make decisions during pregnancy), the Indian surrogate was found to have no decision-making power regarding gestational and birth processes, which rested with doctors and intending parents (Rozée et al., 2019, p. 6). Saravanan (2016) highlighted the limited autonomy that Indian surrogates have over their contract pregnancies, particularly in terms of her say in the matters related to pregnancy, medical procedures, compensation and accommodation arrangement. Modern conceptualisation of autonomy is predicated on Mill's famous maxim that '[o]ver himself, over his own body and mind, the individual is sovereign' (1859/1991, p. 14). The importance of autonomy to law and health-care ethics is clear and, for that matter, presumption of agency underlies the conception of autonomy (Donnelly, 2014, p. 24). Autonomy is an essential constitutive element of agency and the more autonomous a person is, the better one is able to effectively exercise her agency (Maclean, 2009, p. 23). In Indian commercial surrogacy, the fact remains that women entered into contracted pregnancies for the want of money that linked deeply to the notions of coercion and lack of choice and agency. Whether it is a case in which a surrogate found herself majboor (compelled) to sell her reproductive labour to improve her socio-economic condition (Pande, 2009) or whether it is a case in which she exercised pragmatism and saw surrogacy motherhood as a 'better option' than the underpaid work in domestic service or garment factories (Rudrappa, 2012), the surrogate had always been socio-economically weaker than the intended parents and inadvertently vulnerable to exploitation. In fact, unquestionable submission by the surrogate to the terms of the commissioning parents is a hidden criterion in the selection of a surrogate and failure to submit to all medical procedures is considered a breach of contract (Saravanan, 2016, p. 27). 
Informed consent predicated on autonomy allows the patient to act as an autonomous, selfdetermining person who is then obliged to answer for the consequences of those decisions (Dworkin, 2012, p. 102). As a central concept in medical ethics that involves taking consent only after information-sharing and counselling (Tanderup et al., 2015, p. 494), informed consent is quintessential in the context of health-care provision to protect the patient's (in this case the surrogate's) physical and psychological integrity against unwarranted invasion. The signing of the contract is the initial point at which this information-sharing, including the explanation of the medical procedures involved, complications, risks, counselling and obtaining consent, may take place (Tanderup et al., 2015, p. 494). It was noted that, in India, surrogates routinely signed a surrogacy contract following the confirmation of the pregnancies without knowing what would be the case if the pregnancy does not continue beyond two months, putting themselves in a precarious position (CSR, 2012, p. 40). Surrogates were made to undergo a series of tests without being informed about either the number or the purpose of the tests, and almost no information was provided about the actual procedures or the techniques that she would have to undergo beyond the minimal details (SAMA, 2012, p. 62). The case for informed consent in decision-making is even more compelling in the case of surrogacy, which involves a third party, namely the commissioning parents. Studies found that the surrogate had no role in deciding whether or not she wanted to carry the pregnancy, as that decision rested with the commissioning parents, who might have forced her to terminate the pregnancy if they so desired (CSR, 2012, p. 29).

Consent is more than just passively 'permitting something' and requires actively 'giving permission' (Maclean, 2009, p. 113). To that end, it is natural that the patient gains sufficient knowledge to allow her to consent to the proposed procedure or intervention. Whereas she does not really need to know the mechanics of the procedure or the scientific evidence in support thereof, she needs to have sufficient knowledge to 'distinguish [procedure] $\mathrm{X}$ from the alternative in terms of the risks and the effects of the procedure' (Maclean, 2009, p. 134). On the other hand, in Indian commercial surrogacy, empirical studies identified the issue of lack of decision-making in a number of embryo-transfer and foetal-reduction cases, in which the surrogates had little to no information on the risks involved and submitted to the terms of the commissioning parents (Tanderup et al., 2015; CSR, 2012; SAMA, 2012). For example, it was noted that multiple embryos were transferred to the surrogate's womb to increase the success rate of pregnancy, and the decision-making regarding the number of pregnancies rested mostly with doctors and in some incidents with the commissioning parents (Tanderup et al., 2015, p. 491). For consent to be more than passive submission, knowledge of alternatives on offer is crucial for the patient to develop the understanding of the implication of her decision (Maclean, 2009, p. 134). Thus, both lack of knowledge and undue influence (whether coercive or not) are capable of shifting the control over decision-making and invalidate consent (Maclean, 2009, p. 133). Indian surrogates, usually coming from a low economic and educational background who perceived doctors as authority figures, were found to passively submit instead of obtaining full information with quality and clarity. It appeared that agents had a greater part of the responsibility to explain the surrogacy process than the doctors (Tanderup et al., 2015, p. 494). Both lack of information by the doctors of the risks involved and undue influence of the agents had evidently shifted the decisionmaking away from the surrogates in commercial-surrogacy arrangements in India. It did not really make much difference whether the surrogates had no formal education or a relatively higher level of education, as gaining access to information and maintaining communication were challenging, largely because the majority of transactions, including signing consent forms, implementing other protocols and, in some cases, communicating with commissioning parents, were conducted in English. It seriously undermined the giving and receiving of informed consent and the surrogate's participation in an informed decision-making process (SAMA, 2012, p. 40). Even where the surrogates were not the 'poorest of the poor' and did not appear to be 'powerless victims in need of aid', the unequal relationship between the surrogates and medical doctors, as well as between surrogates and rich intending parents, and the existence of exploitation in commercial surrogacy could not be denied (Rozée et al., 2019, p. 6). Exploitation, namely the taking of unfair advantage, such that one individual or 
party gains at another's expense (Kirby, 2014, p. 25), emerged as the constant theme in all the studies set out in the Indian context. As Kirby (2014) noted, provision of inadequate information to surrogates, in particular of the physical health burdens (e.g. associated with hormone manipulation, health risks of multiple-embryo transfer and foetal reduction, risk of maternal mortality, increased risk of borderline epithelial ovarian tumours) and psychological health burdens (e.g. associated with altered living arrangements, giving up the infant whom they delivered), absence of meaningful choice and paternalistic control by the clinics over the surrogate's activities during their pregnancy affirm that exploitative conditions exist in transnational commercial surrogacy in India.

Some commentators (e.g. Wilkinson, 2016) claim that 'paid surrogacy is no worse than many other exploitative commercial transactions which take place against a backdrop of global inequality and constrained options'. Kirby (2014, p. 29), on the other hand, rightfully reasons that 'the limited "freedom" of an individual to make any choice available to her within a transaction, is not sufficient to render that transaction meaningfully autonomous'. Feminist theorists have questioned the social and structural context in which women make decisions and identified the impact that power relations and oppressive social factors have on agency and decision-making freedom (Donnelly, 2014, p. 27). Some radical feminists have even questioned whether female agency is in fact possible. However, this approach invalidates a number of decisions taken by women as non-autonomous, which only perpetuates and rather justifies denial of the decision-making power of people who live in oppressive conditions (Donnelly, 2014, pp. 31-33). Therefore, dismissing a surrogate's decision to enter into or stay with surrogacy as non-autonomous undermines her agency and does nothing to empower her or improve her position in the social structure. In this context, autonomy-building and enhancing agency are better ways of dealing with these concerns. The goal of social development must be the enhancement of autonomy and the development of circumstances in which more people can become fully autonomous. This requires examining policies and practices not only in terms of current autonomy, but also in their ability to empower individuals and develop future autonomy. Thus, autonomy is more than mere non-interference and requires investigation of the decision-making process (Donnelly, 2014, pp. 46-47). This approach to autonomy entails examining whether the proposed surrogacy law ensures that processes protect and facilitate the involvement of surrogates in decision-making.

The present section discussed the legal and socioethical issues that surfaced in transnational surrogacy agreements and set out the context in which the Indian government introduced the Bill. The present discussion highlighted the complex legal issues of nationality, legal parentage and custody rights that led to India's decision to ban international surrogacy. Analysis of academic literature on socioethical concerns further outlined the lack of autonomy, agency and informed consent in transnational commercial surrogacy in India. These studies are underlying the calls for the prohibition of 'commercial' surrogacy arrangements, as well as ensuring the involvement of the surrogates throughout the surrogate pregnancy, in order to enhance her autonomy and agency. However, as the following sections will demonstrate, not only does the Bill provide for legal certainty at the cost of the surrogate's well-being, but it also subjects her to conditions that limit her agency. However, first, the next section presents an outline of the Bill.

\section{The Surrogacy (Regulation) Bill: a short synopsis}

The previous section set out the legal and socioethical concerns that led the Indian government to bring out the Surrogacy (Regulation) Bill with the stated purpose of regulating surrogacy arrangements. Surrogacy, which is defined under section $2(\mathrm{zc})$ as 'a practice whereby one woman bears and gives birth to a child for an intending couple with the intention of handing over such child to the intending couple after the birth', will be outlawed in India in any commercial format once the Bill gets the presidential assent. Under the proposed legislation, any reward, benefit, fees, remuneration or monetary incentive, whether in cash or kind, to the surrogate mother or her dependents or her representative (except the medical expenses incurred by the surrogate mother and the insurance coverage for the surrogate mother) will also not be permissible (s. 3(ii)). It prohibits the selling or buying of 
human embryos or trading in the sale or purchase of human embryos or gametes, or selling or buying or trading in the services of surrogate motherhood (s. 3(ii) read with s. 2(f)). In addition to commercial surrogacy, the Bill further outlaws the promoting, publishing, canvassing, propagating and advertising of commercial surrogacy or inducing women to act as a surrogate mother (ss. 3(ii), (v)). Although storage for other legal purposes like sperm banks, IVF and medical research is permitted, the storage of human embryos or gametes for surrogacy is not permitted (s. 3(vii)). Abusive practices having the potential for exploitation of surrogacy-born children, particularly in unregulated commercial surrogacy, are well documented (UN Report, 2018, p. 9). The Bill therefore goes a step further in specifying that 'no person, organisation, surrogacy clinic, laboratory or clinical establishment of any kind shall exploit or cause to be exploited the child born through surrogacy in any manner whatsoever' (s. 35(1)(c)). Violation of this legal obligation is subject to a penalty of imprisonment for a term that may extend to ten years and with a fine that may extend to up to about $£ 11,500$ (s. 35(2)).

On the other hand, only 'altruistic' surrogacy, where 'no charges, expenses, fees, remuneration or monetary incentive of whatever nature, except the medical expenses incurred on surrogate mother and the insurance coverage for the surrogate mother, are given to the surrogate mother or her dependents or her representative', is now permitted following certain eligibility criteria set out for both the intending couple as well as the surrogate mother-to-be (s. 2(b)). To that end, the Surrogacy Bill creates a regulatory framework through constitution of the National and the State Surrogacy Board(s) and appointment of appropriate authorities. It further establishes a process to regulate surrogacy and matters incidental thereto, such as the registration of surrogacy clinics, parentage and custody issues, offences and penalties, the maintenance of records, etc. (Preamble). In the process to regulate the intermediaries, surrogacy procedures or related activities can only be performed at registered clinics and by qualified medical practitioners (ss. 3(i), (iii), (iv)). Overall, the Bill responds to the novel legal and socioethical challenges that emerged in the unregulated trans-border commercial-surrogacy market. Whereas the Indian government has responded to the challenges of 'nationality' and 'citizenship' of the surrogate-born child, as the next section will demonstrate, safeguarding the legal rights of the intending parents and the surrogacy-born child comes at the cost of the physical and mental well-being of the surrogate. Moreover, the Bill seems to have taken a retrogressive instead of progressive approach in its conception of 'family'.

\section{One step forward or one step back?}

\subsection{Addressing legal challenges in surrogacy: at what cost?}

As noted earlier, unregulated transnational commercial surrogacy raised the legal questions of citizenship, nationality and parentage in situations that were covered neither by surrogacy contracts nor by any existing laws (Gola, 2013). The issue of nationality became particularly relevant in international surrogacy arrangements, since states apply their own domestic laws in determination of 'nationality'. Often, nationality is determined 'by descent' where one of the child's parents is a national of the state (Permanent Bureau, 2012, p. 22). To that end, the Indian government in 2015 banned commercial surrogacy for foreign nationals including non-resident Indians with foreign national status (Government of India, 2017a). 'Altruistic' surrogacy that is now permitted is also available only to Indian nationals (s. 2(g)). Therefore, an Indian surrogate can carry a child for only an Indian intending couple and, accordingly, the child born of surrogacy will remain an Indian national. Article 35 of the Convention on the Rights of the Child (CRC) obliges state parties to take appropriate national, bilateral and multilateral measures to prevent the sale of children for any purpose or in any form. India ratified the CRC in 1992 and a state party is under an obligation to ensure that it prevents any practices that are akin to the sale or trafficking of children in any form. Following incidents such as a convicted sex offender from Israel employing an Indian surrogate mother (Overdorf, 2013) or the abandonment or sale of 'excess' surrogate-born infants in twin births (Ahmad, 2014), prohibiting domestic commercial surrogacy is a step in the right direction. The Bill also stipulates that no surrogacy or surrogacy procedure shall be conducted for producing children for sale, prostitution or any other form of exploitation (s. 4(ii)(d)). 
Another issue is that of natural and legal parentage, since many rights and obligations flow from parents to children. Only the person(s) with legal parentage have parental responsibility towards the child, which became more important in light of stories in which foreign commissioning parent(s) abandoned the surrogate-born child when the child was born with a disability or was an unplanned twin (Government of India, 2017b). In many countries such as the UK, the natural mother (i.e. the one who gives birth to the child) has legal parentage of the child and, as such, the surrogate is the child's legal parent at birth (Gov.UK, undated). However, Indian law takes a different view and aims to settle the issue of parentage by requiring a prior order of parentage and custody for the child to be born through surrogacy. Therefore, a surrogacy procedure cannot be initiated or commenced unless the intending couple and surrogate mother make a joint application regarding the parentage and custody of the child to be born through surrogacy to a court of the magistrate. The order passed by the magistrate is then to be provided by the intending couple to the appropriate authority to obtain the certificate of essentiality. Although the Bill does not have any provision for the 'birth certificate' of the surrogate-born child, the prerequisite of a parental order passed by a court ensures the legal status of intending couple as parents. The Bill, therefore, through imposition of parental responsibilities on the intending couple, aims to protect the interest of the child born through surrogacy. It further reinforces the rights of a surrogate-born child by recognising him/her as the biological child of the intending couple, having the legal rights and privileges of a natural child under the law. The Bill specifically criminalises any form of sex selection for surrogacy (s. 3(viii)) and abandoning of the child born through surrogacy, whether in India or outside, for any reason whatsoever (s. 7). It also provides for custodial sentences of up to ten years and fines of up to about $£ 11,500$ for violating these provisions (ss. 35(1)(c)(g), (2)). Finally, the Bill requires the surrogacy clinics to maintain all records and documents for twenty-five years (s. 43) and the appropriate authority to maintain the details of registration, cancellation, registration and renewal of surrogacy clinics, grant of certificates to the intending couple and surrogate mothers or any other matter pertaining to the granting of licence, etc. of the surrogacy clinics in such a format as may be prescribed (s. 34(2)). A national register, having details from the registration and conduct of every surrogacy clinic, surrogacy arrangements, to all its stakeholders (including gamete donors), taking place across the country, will ensure the effective nationwide regulation of surrogacy. Such a database will also be effective in guaranteeing a child's right to access information about parentage as warranted by Article 7 of the CRC. Above all, these provisions also ensure that intending couples understand and fulfil their parental and legal obligations in respect of the surrogate-born child.

Nonetheless, these safeguards somewhat come at the cost of the well-being of the surrogate mother. In fact, the Bill seems more interested in safeguarding the interest of the intending couple in the bid to avert any legal conflict in case the surrogate changes her mind and claims parentage after the child is born or if the authorities decline to recognise the commissioning parents as legal parents. The legal position of the intending couple as natural and legal parents is further strengthened through the requirement that the surrogate mother shall not provide her own gametes. Barring the surrogate from providing her own gametes narrowly focuses on severing the genetic ties between her and the child to ensure that there are no legal complications as to parentage and custody later on. However, this approach disregards the physical integrity of the surrogate and forces her to go through more invasive IVF procedures, even in cases in which she can get pregnant with a much safer method such as artificial insemination (Shah, 2009, p. 32). Therefore, the Bill ignores the plurality of kinship, particularly motherhood, in a surrogacy arrangement and reduces a surrogate mother to a mere 'gestational carrier', where pre-embryo parentage transfer ensures that the intending couple is listed as the only parent(s) on the birth certificate, whether or not they are genetically related to the child.

In addition to these legal issues, surrogacy arrangements and procedures have also posed a number of socioethical concerns that, as the next section shows, the Bill has only addressed to a limited extent, especially those relating to the surrogate's participation throughout the surrogacy process and therefore her future autonomy and agency. 


\subsection{Addressing socioethical concerns: does the Bill go far enough?}

A number of ethical challenges, including questions of the commodification of bodies, body parts and babies, the conception of kinship and motherhood, and further the medicalisation of childbirth and reproduction, emerged in the era of unregulated and unchecked international commercial surrogacy (Martin, 2009, p. 258). Deonandan et al. (2012) identified ethical issues related to informed consent, quality and limits of surrogate care, remuneration, multiple-embryo transfer and abortion, medical advocacy and exploitation of the poor that are specific to surrogacy in lower- and middle-income countries. As noted earlier, the literature focused mainly on issues related to surrogate autonomy, informed consent and decision-making in commercial-surrogacy arrangements. Further concerns were raised for surrogate mothers who are particularly vulnerable to exploitation due to poverty, lack of education and powerlessness, and were coerced into surrogacy by their husbands in order to support their families or improve their children's lives (Pande, 2009, p. 159). Furthermore, the economic and literary superiority of the commissioning couple along with the unequal bargaining/negotiating power often results in potential surrogates accepting unfair contractual conditions or an unfair price under pressure from the commissioning party or the intermediaries (Rimm, 2009, p. 1459). Unregulated commercial surrogacy (be it international or domestic) has, thus, created a reproduction market economy that is rife with opportunities to exploit poverty-driven surrogates and raises issues of female autonomy and reproductive rights.

As the ethnographic studies highlighted, it is the commercial aspect, namely remuneration, that compelled the surrogates to contract the pregnancies in the first place and then continue with them under the strict conditions set out by the surrogacy clinics or commissioning parents, leading to their exploitation. A reading of section 2(b) with sections 4(ii)(b) and 4(iii)(a)(III) shows that, by outlawing commercial surrogacy and allowing only medical expenses and insurance coverage in altruistic surrogacy, the Bill attempts to address any concerns related to remuneration. Although 'altruistic' surrogacy is understood as a gratuitous act, substantial reimbursements to surrogate mothers and intermediaries may blur the line between altruistic and commercial surrogacy. So, unless the courts or other competent authorities supervise the transactions and are satisfied that the reimbursements are reasonable and itemised, 'reimbursement' may be a disguised payment for transfer of the child, particularly in the case of very poor surrogates (UN Report, 2018, p. 16). In this regard, an embargo on any 'charges, expenses, fees, remuneration or monetary incentive of whatever nature, except the medical expenses incurred on surrogate mother and the insurance coverage for the surrogate mother' under section 2(b) attempts to sufficiently delineate commercial and altruistic surrogacy. The Bill also prohibits the commercialisation of any other component services or procedures related to commercial surrogacy, such as canvassing, advertising, publishing or promoting commercial surrogacy, recruiting surrogates or inducing women to act as a surrogate mother, etc. (s. 3(v)). Whereas clinics can store a human embryo or gamete for legal purposes such as sperm banks, IVF and medical research, their use for surrogacy is prohibited (s. 3(vii)). Thus, the Bill outlaws any practices that are associated with or may even inadvertently lead to commercial surrogacy. The Bill extensively regulates medical intermediaries, namely surrogacy clinics, by providing not only an extensive procedure for registration and compliance, requiring maintenance of all records, charts, forms, reports, consent letters, agreements and all the documents for a period of twenty-five years, and inspection by an appropriate authority, but also a complaints mechanism (ss. 10-13, 43). So, not only the appropriate authority, but any person including a social organisation can bring a complaint against a surrogacy clinic to the court (s. 41(1)(b)). It is believed that social vigilance will help to keep a check on commercialsurrogacy practices and procedures.

It cannot be denied that reimbursement can be a disguised remuneration and illegal inducement, yet a very narrow conception of reimbursement and insufficient compensation as seen in the Bill is equally problematic. This approach undermines the risks for surrogates and accentuates the issues of the quality and limits of surrogate care. Surrogacy is not a single act of medical intervention, but a heavily medicalised process in a continuum that starts with a thorough medical examination 
prior to the process of preparing the surrogate's body for the IVF technique. A number of tests, some of which encompass invasive medical interventions, check her hormone levels and uterine lining to ensure her fitness for the surrogate pregnancy (SAMA, 2012, p. 61). Thereafter, the surrogate's own ovulatory cycle is suppressed using hormone shots followed by oestrogen shots to build her uterine lining (CSR, 2012, p. 14). Since the general success rate of IVF implantation is not very high, surrogates are often put through a number of cycles before a successful pregnancy takes place (SAMA, 2012, p. 64). Thereafter comes the decision about the number of implants to use to improve the success rate. Even when impregnated, she has to continue taking daily injections of progesterone until her body is ready to sustain the pregnancy on its own (CSR, 2012, p. 14). The process culminates with the delivery of the baby where the push for caesarean sections has become the norm in ART deliveries, clearly increasing the risks for surrogates. Furthermore, the changes that a surrogate has to make to her lifestyle, from her diet to daily physical activities, while fulfilling her regular domestic familial duties or giving up her work, and the extent to which the stresses of these dual roles are dealt with by the intending couple and clinicians, is also an issue of ethical consideration (Deonandan et al., 2012, p. 743). In the realm of unregulated commercial-surrogacy agreements, the Indian judiciary has increasingly favoured commissioning parent(s) in determining the commissioning mother as the 'legal mother', entitling her to 'maternity benefits' (see e.g. K. Kalaiselvi v. Chennai Port Trust, W.P.No.8188/2012, decided on 4/3/2013; Sadhna Agrawal v. State of Chhattisgarh, W.P.(S)No.4927/ 2016, decided on 3/01/2017). Since the Bill also ensures that the intending mother is the legal mother (and thus entitled to maternity benefits), it exposes a passivity towards the surrogate mother who has actually undergone the physical labour of carrying the fertilised embryo from conception to birth. If she is a working woman, what is her entitlement to maternity leave or any time off to recover both physically and mentally? Carrying a child to full term and giving birth are both physically and mentally taxing, especially in full surrogacy, where women have to undergo painful hormonal stimulation. Post-partum injury is a foreseeable direct result of the process (be it by natural birth or through caesarean section) begun by the clinician when retrieving the biological product (the child) for their client (the intending couple). Given the likelihood of post-partum injury (or depression), it is not clear who is ultimately responsible for assuring sufficient care for the safe recovery of the surrogate (Deonandan et al., 2012, p. 743). As noted earlier, research has increasingly revealed the deep emotional and physical ties that develop between the surrogate and the child, and the significant emotional trauma of giving up the child (Pande, 2009, p. 143). Whereas the Bill provides for insurance cover for a period of sixteen months covering post-partum delivery complications (s. 4 (iii)(a)(III)), it does not consider the issues of the requisite care and loss of earnings (where applicable) and, as such, does not go far enough to safeguard the physical and emotional welfare of the surrogate. Nor does the insurance provide for any social security in case of unforeseen contingencies such as accidental death of the intending parents or divorce during the process of surrogacy (Standing Committee Report, 2017, p. 23). In fact, the Bill seems to maintain the mere 'gestational-carrier' approach towards a surrogate, which seems to 'un-mother' the surrogate by denying her any post-partum care or consideration.

Informed consent and participation in pregnancy related to decision-making have been particularly problematic, especially in light of the fact that surrogates often are of limited literacy and driven by economic needs. Informed consent involves endeavours to avoid coercion (both subtle and overt) through the communication of risks and benefits, and emphasises the quality and clarity of communication (Deonandan et al., 2012, p. 742). As noted above, the issues related to informed consent are present throughout, from the point of entering into the surrogacy contract until the decision about the mode of childbirth. Surrogates often sign a consent form (in English, a language that many cannot read) after being made to understand in essence (1) that they have no claim over the baby; (2) that they will have to hand over the child right after it is born; (3) that the doctor or the couple is not responsible for any death resulting from the process; and (4) how the payment will be made. The information about the procedure involved and the medication is often provided by a surrogacy counsellor once the contract is signed (Pande, 2009, p. 147). Moreover, the surrogates had no say in the number of embryos to be transferred, which often resulted in multiple pregnancies and then 
foetal-reduction abortions. Multiple-embryo transfer to maximise the probability of a successful implantation and thus reduce the cost to the client is not an uncommon occurrence in surrogacy arrangements. It then raises the possibility of selective-reduction abortions for several medically defensible reasons. Unquestionably, multiple pregnancies is a dangerous medical condition and comes at a great risk for the surrogate's body and well-being (Deonandan et al., 2012, p. 744).

In terms of informed consent, the Bill ensures that all known side effects and after-effects of surrogacy procedures are explained to the surrogate mother-to-be. In addition, the surrogate is to give her consent in the prescribed form written in the language that she understands. Finally, she is entitled to withdraw her consent at any stage after signing the form but prior to implantation of an embryo into her womb (s. 6). The Bill further requires her to produce a certificate of medical and psychological fitness for surrogacy and surrogacy procedures from a registered medical practitioner before the surrogacy procedure is undertaken (s. 4(iii)(b)(v)). This requirement appears to ensure that the surrogate mother is capable of coping with the physical and psychological after-effects of oocyte/embryo implantation. In terms of the number of embryos to transplant, the Bill allows multiple implantations, although it leaves the decision on the number of oocytes or embryo implantations to the central government to be made later via rules to carry out the provisions of the Act (ss. 8, 47(f)). Whereas a woman can act as a surrogate to only once in her lifetime (s. 4(iii)(b)(IV)), the number of attempts for surrogacy procedures and the number of oocytes or embryos to be implanted shall be such as may be prescribed by law (ss. 8, 47 (f)). Finally, the Bill ensures that the surrogate mother should not be forced to abort at any stage of the surrogacy except under such conditions as prescribed by the rules to be made by the central government at a later stage (ss. 9, 47(g)). Section 3(vi) provides an additional safeguard by placing a duty on the clinics to obtain written consent of the surrogate before conducting abortion along with the authorisation of the same by the appropriate authority (subject to compliance with the provisions of the Medical Termination of Pregnancy Act, 1971).

Consent, as Gillon states, 'means a voluntary, uncoerced decision, made by a sufficiently competent or autonomous person on the basis of adequate information deliberation, to accept rather than reject some proposed course of action that will affect him or her' (1986, p. 113). Although the Bill requires all known side effects and after-effects of the surrogacy procedure to be explained to the surrogate, for the consent to be truly informed, she must also be given the information regarding the success rate for the pregnancy and the alternative of failed pregnancy and multiple cycles that she may have to undergo. Since our bodies are so fundamental to our self-identity and autonomy, the patient cannot be held to her consent and, therefore, it must be accepted that the person giving consent to a breach of bodily integrity may unilaterally withdraw their consent (Maclean, 2009, p. 112). The Bill, permitting the surrogate to withdraw her consent for surrogacy, affirms her status as an autonomous person having agency over her body. On the other hand, limiting the consent to the point prior to implantation of the embryo seems not to acknowledge the importance of the consent of the surrogate during the pregnancy including the decision regarding the mode of delivery. Moreover, it does not ensure that the surrogate is part of the decision in relation to the number of embryo implants, namely that, despite the number of embryo implants to be prescribed by the rules, the rules must also provide that the surrogate actively 'gives permission' and does not passively 'permit' the number of embryos to be implanted into her womb. It means that the law must actively challenge the persistent and entrenched culture of paternalism that tends to exclude surrogates by limiting information and discouraging them from asking questions as is evident from surrogates' experiences in commercial surrogacy. Moreover, in light of the issues regarding the absence of medical ethics as are evident from the ethnographic studies, the format of written consent that is to be prescribed by the rules (s. 47(e)) must also ensure that informed consent cannot be used to vitiate the legal and moral responsibilities of the clinics.

In terms of decisions regarding the number of embryo implants that were often made to ensure a successful pregnancy at the cost of high risk to the surrogate, regulation of the numbers of surrogacy procedures and embryo implants takes the arbitrariness out of this equation and is intended to provide a safeguard by allowing only as many implants as are deemed essential for a successful surrogacy. At the same time, the Bill does not seem to acknowledge the possibility of conflict arising from 
multiple-embryo implantations and resulting selective abortions even in a well-regulated altruisticsurrogacy arrangement. What if the multiple-embryo implants result in twins or triplets, whereas the intending couple wish only for a single child? In such a situation, the surrogate mother's refusal for reduction abortions will not only result in conflict, but also poses questions of legal parentage and the upbringing costs of children born of surrogacy. Such scenarios are not unusual, as the American case of Cook v. Harding (190 F. Supp. 3d 921 (C.D. Cal. 2016)) demonstrates. In this case, three embryos were transferred to the surrogate, leading to a triplet pregnancy. The conflict arose when the intending father refused to pay for the high-risk triplet pregnancy and demanded a reduction abortion that was refused by the surrogate mother. By refusing to reduce, she was claimed to be in breach of the contract and liable for monetary damages, including the medical treatment for a resulting child. Whereas this case was related to a commercial contractual surrogacy, the challenge it poses for altruistic-surrogacy arrangements remain. The present Bill seems not to envision such a scenario and, as such, it is not clear what outcome will follow. Given that the intending couple is to obtain a parental order from a court prior to conception, will that order cover only one child or all the children born out of the gestational surrogacy? What if the surrogate mother wishes to keep one child out of an unwanted twin/triplet pregnancy? Although a surrogate cannot be forced to abort and no abortion can be performed without her written consent, it is not clear whether she will have any claim over the additional children born out of surrogacy, irrespective of whether or not they are wanted by the intending couple. Furthermore, the Bill claims to protect the interests of surrogate and surrogate-born child, yet it overlooks the possibility of exceptional circumstances such as the breakdown of the relationship between the intending couple or their death and, as such, fails to provide for any social insurance to mitigate the precarious circumstances that the surrogate or the surrogate-born child may find themselves in (Standing Committee Report, 2017, p. 23).

In terms of regulating 'altruistic' surrogacy, the Indian government seems to have gone a step backwards, particularly in setting out the eligibility criteria for the intending couple and surrogate mother to enter into altruistic-surrogacy arrangements. Sections 4(iii)(c)(I-II) stipulate that only Indian couples of a certain age (woman between twenty-three and fifty years old and men between twenty-six and fifty-five years old), married for at least five years, can enter into surrogacy arrangements. Section 4(iii)(a)(I) requires the intending couple to first obtain a certificate of proven infertility (of either or both partners) from a District Medical Board. Following section 4(iii)(c)(III), the intending couple must also not have any surviving child unless the child they have is physically or mentally challenged or suffers from a life-threatening condition or fatal illness. Only an ever-married woman aged between twenty-five and thirty-five years old with a child of her own and who is a close relative of the intending couple can act as a surrogate or help in surrogacy. Whereas a woman can help in surrogacy by donating her egg or oocyte or otherwise, she cannot provide her own gametes if she is acting as a surrogate mother (s. 4(iii)(b)). Thus, the Bill outlaws conception by a fertile male intending parent with the surrogate mother's egg. The Bill further requires both the intending couple and the surrogate to furnish eligibility certificates confirming the above criterion before undertaking the surrogacy procedure. All in all, the Bill sets out a proper outline for a traditional heteronormative family idealised by the traditionalists altogether overlooking the fact that we are now in the twenty-first century and that the concept of family has changed drastically in the modern era.

Families in the twenty-first century are no longer static, but living, breathing and evolving social and legal entities that have challenged all preconceived notions of a traditional heteronormative family. Another layer of complexity is added through the use of technology and human ingenuity where children may or may not be genetically related to their legal parent(s) (either through adoption, IVF treatment or surrogacy). Surrogacy has been particularly advantageous in the formation of a single-parent family or in same-sex marriages, since it is the only way in which a gay couple or a single man can have a genetically related/biological child. Therefore, 'family' is no longer a given concept, but an institution that is changing constitutively. These modern families defy the patriarchal constructions of gender identities and roles by questioning the perceptions, such as that only women are suitable for the role of a mother. Such a notion does not fit with the family of a gay male couple or a single man 
raising children (SAMA, 2012, p. 17). Although the perception of family has not changed in Indian society very much, the acknowledgement of live-in relationships and the recent decriminalisation of homosexuality by the Indian Supreme Court indicate the gradual societal move towards the acceptance of universal human rights, including the reproductive rights of the LGBTQ community. On the other hand, the proposed Indian law excludes homosexual couples, single persons and live-in couples from accessing 'altruistic' surrogacy on the pretext that allowing surrogacy for homosexuals/singles/live-in couples will lead to misuse of these facilities. The Indian government is of the view that, since raising a child is a lifelong responsibility and a child needs both a mother and a father, a single person may not be able to fulfil his/her responsibility completely. In response to the Parliamentary Committee's questions, the ministry drafting the Bill reasoned that, given the lack of any legal recognition of gay or live-in couples, they may split up at any time and it will create complications if such a decision is made mid-surrogacy. Finally, the government justified the exclusion of single persons and homosexuals on the basis that such surrogacy will need a third-party gamete (sperm or eggs) donor and, as such, it may further create legal complications and custody battles at a later stage (Standing Committee Report, 2017, p. 17). These eligibility criteria that allow only a married heterosexual couple to commission a surrogacy and require that only a heterosexual woman married to a male can act as a surrogate reiterate the heteronormative perception of family and restrict reproductive choices for the LGBTQ community. Heteronormative discourse reinforces ideas of socially acceptable subjects and reinforces current social exclusions (Garwood, 2016). The traditionalist approach supports reactionary conservatives' criticism of individual human rights as being antithetical to social order (Howard, 1995, p. 2). On the other hand, traditionalists turn a blind eye to inequities and the violation of individual human rights when those rights conflict with traditional values. In this era in which the institution of 'family' is evolving, the proposed legislation showcases a retrogressive approach in the governance of surrogacy. Cultures, traditions and religions are constantly evolving in any living society responding to internal and external stimulations, with many new customs outmoding the old values and beliefs. Certain concepts, such as law and justice, individual dignity, the protection of life and liberty, the legitimacy of government and protection from oppressive arbitrary rules, are valued across societies, nations and cultures. These values are thus common denominators that found the universal human rights intrinsic to every individual by virtue of being human (Tharoor, 1999). It is true that some of the concerns raised by the government are valid to an extent, particularly in the absence of any specific regulations, yet a blanket exclusion overlooks the needs of a wide section of society and restricts their reproductive choices and autonomy. If anything, these concerns require review and revision of the Indian family law that governs issues around children, personal relationships, relationship breakdown and children in the context of divorce or separation. It is true that reproductive autonomy does not mean a right to a child. There is no 'right to a child' in international law, as a child is a rights-bearing human being, not goods or a service that the state is bound to guarantee (UN Report, 2018, p. 15). Nonetheless, a number of countries (such as Greece, New Zealand, Israel and South Africa) that regulate altruistic surrogacy acknowledge a 'social' need for surrogacy, despite their different social and cultural norms, and allow surrogacy for same-sex male couples and single males (Permanent Bureau, 2012, p. 14). Moreover, the right to 'found a family' is an internationally acknowledged human right (see e.g. the International Covenant on Civil and Political Rights, Art. 23(2)). Above all, such discrimination is against the fundamental right to equality enshrined in the Indian Constitution that guarantees equality before law, namely that there shall be no discrimination between one class of citizen and another. It is the duty of the state to bring about, through the machinery of law, a more equal society as envisioned in the Indian Constitution (Srinivas Theatre v. State of T.N., 1992 AIR 999). Discriminating against single persons and the LGBTQ community in accessing 'altruistic' surrogacy not only violates their right to reproductive autonomy, but also goes against the letter and spirit of the Indian Constitution. Therefore, in allowing 'altruistic' surrogacy, the proposed legislation must concede the right to found a family of all men and women, irrespective of their marital status or sexual orientation.

The present Bill is equally restrictive in terms of allowing who can act as a surrogate. Only a married woman, a 'close relative', of a certain age (twenty-five to thirty-five years old) with a 
child of her own can either be a surrogate or help in surrogacy by donating her egg or oocyte (s. 4 (iii)(b)(I)). These restrictions are justified to protect surrogates from exploitation, yet their overarching limitations are paternalistic and raise issues of agency and freedom of reproductive choices. For example, while constraining 'altruistic' surrogacy to close family relatives, the Bill does not define what being a 'close relative' actually means. Is the relation to be of blood or through marriage? How many degrees of separation will take the relation outside the purview of 'close'? By requiring the surrogate to be married, the Bill once again perpetuates the heteropatriarchal structure in which a woman's marital status becomes important if she wants to bear a child. At the same time, acknowledging that a woman is not the property of her husband, the Bill does not require the consent of the husband to enter into surrogacy arrangements nor does it require his participation in the application for a parental order. This requirement of the surrogate to be married and yet not require her husband's consent for entering into surrogacy arrangements creates a strange paradox and overlooks the social and legal realities of the role of the husband in existing commercial surrogacy. A CSR study (2012, p. 34) noted that all the surrogates in that study belonged to a male-headed household and became surrogate mothers with their husband's approval. It also found that, in most cases, surrogates were emotionally pressurised by their husbands to undergo surrogacy in order to improve their financial status (CSR, 2012, p. 39). Some studies even suggested that, due to their lack of agency in deeply patriarchal households and social settings, surrogates hardly ever know about the remuneration, since their husbands control every aspect of the negotiations (Pande, 2009, p. 159). Another study revealed surrogates' constraints in challenging the existing norms or rather drawing on the power and security that 'being in a heterosexual marital relationship' provided (SAMA, 2012, p. 35). The Bill acknowledges that the surrogates may be forced into contractual pregnancies and accordingly forbids the husband (or any other relative) from compelling her to enter into commercial surrogacy (s. 5) and provides for a penal provision for breaching this obligation (s. 39 read with s. 37). At the same time, it is not clear whether the surrogate has any remedy if she is pressured into entering into 'altruistic' surrogacy.

Finally, despite being a socio-contractual arrangement, surrogacy operates within the wider ambit of ARTs. There are no separate surrogacy clinics, as generally surrogacy services are offered and conducted by ART clinics. The Bill also defines a surrogacy clinic as a clinic, centre or laboratory conducting ART services (s. 2(zd)). Therefore, the role of medical intermediaries in surrogacy arrangements and the need to regulate ART clinics is paramount to the efficacious regulation of 'full' 'altruistic' surrogacy. The draft Assisted Reproductive Technologies (Regulation) Bill 2014 defined surrogacy more broadly as

'an arrangement in which a woman agrees to a pregnancy, achieved through assisted reproductive technology, in which neither of the gametes belong to her or her husband, with the intention to carry it and hand over the child to the commissioning couple for whom she is acting as a surrogate.' (ART Bill 2014, s. 2 (zq))

On the other hand, the definition of surrogacy in the present Bill is limited to the process of carrying the pregnancy and handing over the child to the commissioning parent. The definition in the Surrogacy Bill is not comprehensive, as it fails to take into account all the salient features of surrogacy, such as the question of the gamete belonging to the surrogate or her husband (Standing Committee Report, 2017, p. 24). Although the ART Bill 2020 does not define surrogacy at all, it is recommended that the definition of surrogacy in the Surrogacy Bill is broadened to ensure that the gametes of the husband of the surrogate are not used in the surrogacy arrangement. The Bill must also include the husband of the surrogate to be party to the joint application for the transfer of parentage and custodial order that is currently to be made by the surrogate and the intending couple (s. 4(iii)(a)(III)). Furthermore, it is indispensable that both laws define terms (such as surrogacy) identically to ensure a thorough and consistent legal understanding of the concepts. 


\section{Conclusion}

Surrogacy as a reproductive practice is gaining ground both in India and internationally (UN Report, 2018 , p. 4). States like the UK are in the process of reviewing their surrogacy laws in light of the significant increase in the number of surrogacy arrangements to bring it in line with the changing social attitudes and make the current laws compatible with the European Convention on Human Rights (Law Commission, 2017). The commercial-surrogacy industry thrives on the social stigma around 'infertility' and people's primitive desire to have their 'own' children (Mandal, 2017). It reduces women's bodies to interchangeable gestational carriers and children into end products of a surrogacy service. The ban on commercial surrogacy as well as the proposed regulatory regime in India is opposed on the basis that making the surrogacy services difficult for Indian couples in need will drive the process underground and could lead to more exploitation of socio-economically vulnerable women (Bhattacharyya, 2016, p. 15). Some worry that, by allowing only 'altruistic' surrogacy, the law induces women in a family to offer their reproductive labour to their childless relatives for free (Mandal, 2017). Some scholars even raise the human rights arguments, namely that the right to life enshrines the right to reproductive autonomy including the right to procreation and, as such, the decision on the mode of parenthood lies with an individual and should be free from state interference (Mitra, 2018, p. 115). The right to found a family does not extend as far as 'the right to a child', as a child is not goods or a service, but a 'rights-bearing' human being (UN Report, 2018, p. 15). Research has also revealed that abusive and exploitative practices remain a norm, even within the professedly well-regulated commercial-surrogacy jurisdictions. For example, a prominent surrogacy attorney who was found guilty in a baby-selling ring in California admitted the existence of a 'corrupt' 'billion dollar industry' (UN Report, 2018, p. 9). Moreover, as the Special Rapporteur to the Human Rights Council noted, commercial surrogacy in which parentage issues are decided exclusively on a contractual basis wherein the transfer of parentage as well as the physical transfer of the child after birth is usually a central part of the legal consideration for which the gestational surrogate is paid is akin to the sale of children (UN Report, 2018, p. 12).

The present paper set out to examine the extent to which the proposed legislation to regulate surrogacy in India has addressed the legal and socioethical challenges. By outlawing the commercial aspect of surrogacy arrangements, the Bill seeks to regulate an industry that generates over 2 billion dollars annually (Standing Committee Report, 2017, p. 1). Although the Bill succeeds in addressing some of those concerns that prevailed in the absence of any regulation, the discussion of the provisions of the Bill revealed that it has not gone far enough to safeguard the interests of the surrogate and foster surrogates' autonomy and agency. Autonomy, as noted earlier, is not just about non-interference by the state, but also about using laws to empower individuals and develop future autonomy. Therefore, any legal regime having implications for reproductive autonomy and choice must focus on empowering women to ensure that they are given complete autonomy to exercise control over their bodies and reproductive processes. On the contrary, the paper noted a number of provisos in the proposed Bill that restrict and/or undermine the reproductive autonomy of both the prospective parent(s) and the surrogate.

To begin with, the very eligibility criteria for intending couples demonstrating a narrow conception of family by allowing only a heterosexual married couple to access surrogacy services need to be reviewed. This heteronormative perception of family founded in binary gendered sexual orientation and social hegemony of marriage disregards the right to family of homosexual as well as of single people. Since homosexuality is now decriminalised, it is imperative that the Government of India respects the inherent human rights and reproductive autonomy of the LGBTQ community and removes the requirement of marriage and sexual orientation to access surrogacy services. To that end, the Indian surrogacy legislation can draw upon the Human Fertilisation and Embryology Act (HFEA) 2008 (Part 2) that acknowledges the pluralism of parenthood in surrogacy arrangements. HFEA 2008 (ss. 54-54A) permits the application for a parental order irrespective of the sexual orientation and marital status of the applicant(s) and can be looked at for bringing the LGBTQ community 
and single persons within the eligibility criteria. Expanding the ambit of the Bill to make 'altruistic' surrogacy available to all, irrespective of their marital status or sexual orientation, not only upholds the reproductive autonomy and respects the right to found a family, but also brings the Bill in tune with the current times.

Second, the paternalistic imperative requiring the surrogate to be married undermines the reproductive autonomy and agency of a woman in her own rights by imposing the social norm of marriage upon her. The legal requirement of marriage undermines female autonomy over her body. Not requiring the husband's consent to enter into a surrogacy arrangement is not enough to recognise the surrogate as an autonomous agent. This traditional approach to surrogacy in fact ignores the social and cultural constraints on the agency of a married woman within Indian society. This paradoxical view of female social and reproductive autonomy in the Bill needs to be addressed to ensure that surrogates are not pressurised into 'altruistic' surrogacy. To enable this, it is recommended that (1) the marital requirement for a woman to be able to surrogate is removed and (2) if a surrogate is already married, the gametes of her husband are not used in the surrogacy arrangement, and he is made party to the application to transfer the parentage and custody of the child to be born through surrogacy under section 4(iii)(a)(III).

The value of reproductive autonomy, namely the ability to be self-determining and to act on one's own desires and values in making decisions concerning reproduction (Taluja and Simran, 2018, p. 168) in law and policy, cannot be understated. Medical advances in the reproductive market have led to greater state intervention in an individual's reproductive decision-making. Whereas legal intervention is often necessary to protect individual rights and interests (in surrogacy law, those of the surrogate, intending parents and the child born of surrogacy), if the regulation goes too far, it restricts the same interests that it aims to protect, as we can see in case of the Surrogacy Bill. Moreover, in the bid to pre-empt the legal issues of custody and parentage, the Bill reduces the surrogate to a mere gestational carrier by barring her from using her own gamete as well as denying her any incentive of motherhood such as maternity benefit or post-partum care. As the UN Report noted, this legal fiction of 'never-a-mother' that reduces a surrogate to a gestational carrier is not only used to justify the denial of the surrogate mother's rights; it also opens the door to enforcing contracts that astutely alienate her rights and freedoms (e.g. the right to health and the right to freedom of movement) (UN Report, 2018, p. 14). Whereas it is important that reimbursements are not disguised remuneration, a narrow conception of compensation is equally problematic and undermines the risks for surrogates. Acknowledging the maternal pluralism in the surrogacy arrangements, it is recommended that the Bill recognises the surrogate as a mother, entitling her to the statutory maternity benefits as well as post-partum care. Once again, inspiration may be drawn from the HFEA 2008, which imparts the status of the legal mother on the surrogate (s. 33(1)), yet acknowledges the possibility of another woman as a second parent (s. 44). If the Indian government is really concerned with 'protecting the rights and interests of the surrogate mother' as it claimed in parliament (Government of India, 2016), then it is imperative that the proposed surrogacy law goes all the way to safeguarding surrogates' well-being, protecting and promoting her reproductive autonomy throughout the surrogacy process, and ensuring her future autonomy.

Conflicts of Interest. None

Acknowledgements. I would like to thank my colleagues at Exeter Law School, in particular, Dr Naomi Hawkins, Dr Stephen Skinner, Dr Kyriaki Noussia and His Hon David Tyzack Q.C. for their comments and guidance.

\section{References}

Ahmad A (2014) Child trafficking row after surrogate baby 'abandoned' in India. BioNews, published online 13 October. Available at https://www.bionews.org.uk/page_94777 (accessed 12 December 2021).

Bhattacharyya R (2016) Draft Surrogacy (Regulation) Bill 2016: rhetoric or surrogate-centric? Space and Culture, India 4, 9-21. CSR (Centre for Social Research) (2012) Surrogate Motherhood - Ethical or Commercial. New Delhi: CSR. 
Deonandan R, Green S and van Beinum A (2012) Ethical concerns for maternal surrogacy and reproductive tourism. Journal of Medical Ethics 38, 742-745.

Donnelly M (2014) Healthcare Decision-making and the Law. Cambridge: CUP.

Dworkin G (2012) The Theory and Practice of Autonomy. Cambridge: Cambridge University Press.

Garwood E (2016) Reproducing the homonormative family: neoliberalism, queer theory and same-sex reproductive law. Journal of International Women's Studies 17, 5-17.

Gillon R (1986) Philosophical Medical Ethics. London: John Wiley \& Sons.

Gola S (2013) Reproductive tourism in 'incredible India': socio- ethical \& legal side effects of market-oriented fertility services. Journal of Law Teachers of India 4, 40.

Gomez VR (2014) Surrogacy from a reproductive rights perspective: the case of India. Autrepart 70, 185.

Gov.UK (undated) Surrogacy: legal rights of parents and surrogates. Available at https://www.gov.uk/legal-rights-when-usingsurrogates-and-donors (accessed 24 September 2020).

Government of India (2016) Answer to the Parliament Question number 2208, 6 May.

Government of India (2017a) Answer to the Parliament Question number 3395, 4 August.

Government of India (2017b) Answer to the Parliament Question number 5661, 7 April.

Haworth A (2007) Surrogate mothers: womb for rent. Marie Claire, published online 29 July. Available at https://www.marieclaire.com/politics/news/a638/surrogate-mothers-india/ (accessed 12 January 2021).

Howard RE (1995) Human rights and the search for community. Journal of Peace Research 32, 1-8.

Jaiswal S (2012) Commercial surrogacy in India: an ethical assessment of existing legal scenario from the perspective of women's autonomy and reproductive rights. Gender, Technology and Development 16, 1-28.

Kirby J (2014) Transnational gestational surrogacy: does it have to be exploitative? American Journal of Bioethics 14, $24-32$.

Law Commission (2017) Thirteenth Programme of Law Reforms (Law Com No 377). Available at https://assets.publishing. service.gov.uk/government/uploads/system/uploads/attachment_data/file/668113/13th-Programme-of-Law-Reform.pdf (accessed 12 January 2021).

Maclean A (2009) Autonomy, Informed Consent and Medical Law. Cambridge: CUP.

Majumdar A (2014) The rhetoric of choice: the feminist debates on reproductive choice in the commercial surrogacy arrangement in India. Gender, Technology and Development 18, 275.

Mandal S (2017) An 'Official' Family: Laws Of Parenthood In India, 8 May 2017. Available at https://www.firstpost.com/longreads/an-official-family-laws-of-parenthood-in-india-3425626.html (accessed 28 December 2020).

Martin LJ (2009) Reproductive tourism in the age of globalisation. Globalization 6, 249-263.

Mill JS (1991) On liberty (London 1859). In Grey J (ed.), On Liberty and Other Essays. Oxford: OUP.

Mitra P (2018) Invisible women in reproductive technologies: critical reflections. Indian Journal of Medical Ethics 3, 113-119.

O’Connor A (2007) The white parents, an Indian baby and the new $£ 3$ bn fertility tourism, The Times, 9 February. Available from https:/www.thetimes.co.uk/article/the-white-parents-an-indian-baby-and-the-new-pound3bn-fertility-tourism-p6xx32782lr (accessed 10 December 2020).

Overdorf J (2013) Israeli sex offender taps India's booming surrogacy trade for baby girl, GlobalPost, 10 June. Available from https://www.pri.org/stories/2013-06-10/israeli-sex-offender-taps-indias-booming-surrogacy-trade-baby-girl (accessed 10 December 2020).

Pande A (2009) Not an 'angel', not a 'whore': surrogates as 'dirty' workers in India. Indian Journal of Gender Studies 16, $141-173$.

Parliamentary Standing Committee on Health and Family Welfare (2017) One Hundred Second Report: The Surrogacy (Regulation) Bill, 2016. New Delhi: Parliament of India (Standing Committee Report).

Permanent Bureau (2012) A Preliminary Report On The Issues Arising From International Surrogacy Arrangements, Hague Conference on Private International Law, General Affairs and Policy, Prel. Doc. No 10.

Rimm J (2009) Booming baby business: regulating commercial surrogacy in India. University of Pennsylvania Journal of International Law 30, 1429-1462.

Rozée V, Unisa S and de La Rochebrochard E (2019) Sociodemographic characteristics of 96 Indian surrogates: are they disadvantaged compared with the general population? PLOS ONE 14, 1-9.

Rudrappa S (2012) India's reproductive assembly line. Context 11, 22.

SAMA - Resource Group for Women and Health (2012) Birthing A Market: A Study on Commercial Surrogacy. New Delhi: Impulsive Creations.

Saravanan S (2016) Transnational surrogacy and objectification of gestational mothers. EPW Economic \& Political Weekly XLV, 26-29.

Shah C (2009) Regulate technology, not lives: a critique of the draft ART (regulation) Bill. Indian Journal of Medical Ethics VI, 32-35.

Smith N (2015) Towards a queer political economy of crisis. In True J and Hozic A (eds), Scandalous Economics: The Spectre of Gender After Global Financial Crisis. New York: Oxford University Press, pp. 231-246.

Taluja IK and Simran (2018) Reproductive autonomy and related sexual freedom in India. International Journal of Law and Legal Jurisprudence Studies 4, 166-183. 
Tanderup M et al. (2015) Reproductive ethics in commercial surrogacy: decision-making in IVF clinics in New Delhi. Bioethical Inquiry 12, 491-501.

Tharoor S (1999) Are human rights universal? World Policy Journal XVI. Available at http://worldpolicy.org/2009/11/11/ tharoor-are-human-rights-universal-world-policy-journal-world-policy-institute/ (accessed 28 December 2020).

Twine FW (2015) Outsourcing the Womb: Race, Class and Gestational Surrogacy in a Global, Market. New York: Routledge. UN General Assembly Human Rights Council (2018) Report of The Special Rapporteur on The Sale And Sexual Exploitation of Children, Including Child Prostitution, Child Pornography And Other Child Sexual Abuse Material. UN Doc A/HRC/37/ 60. New York: United Nations (UN Report).

Wilkinson S (2016) Exploitation in international paid surrogacy arrangements. Journal of Applied Philosophy 33, $125-145$.

Cite this article: Gola S (2021). One step forward or one step back? Autonomy, agency and surrogates in the Indian Surrogacy (Regulation) Bill 2019. International Journal of Law in Context 17, 58-74. https://doi.org/10.1017/ S174455232100001X 